\title{
Transport and social exclusion: investigating the possibility of promoting inclusion through virtual mobility
}

\author{
Susan Kenyon $^{1 *}$, Glenn Lyons ${ }^{1}$ and Jackie Rafferty ${ }^{2}$ \\ ${ }^{1}$ Transportation Research Group, Dept. of Civil and Environmental Engineering, University of \\ Southampton SO17 1BJ \\ ${ }^{2}$ Centre for Human Service Technology, Dept. of Social Work Studies, University of \\ Southampton SO17 1BJ
}

\begin{abstract}
This paper introduces a mobility dimension to social exclusion, suggesting a strong correlation between a lack access to adequate mobility and lack of access to opportunities, social networks, goods and services. This correlation exists as both a cause and consequence of social exclusion. The authors question the likelihood that increased physical mobility, by car or public transport, can, by itself, provide a fully viable or sustainable solution to mobilityrelated aspects of social exclusion. This paper cautiously suggests that the use of information and communications technologies could enable a new, virtual mobility, enabling an Internetbased increase in accessibility as an alternative to an increase in physical mobility. Finally, consideration is given to the possibility of a virtual mobility-related dimension of exclusion and to the possible social implications of inclusion of virtual mobility in an integrated transport strategy.
\end{abstract}

\footnotetext{
* Corresponding author, fax 0238059 3152, email s.kenyon@soton.ac.uk
} 
Keywords: accessibility; virtual mobility; social exclusion, information and communications technologies (ICTs); Internet

\section{Introduction}

The objective of this paper is to consolidate current literature and understanding regarding the relationships between social exclusion and transport, before introducing new, at this stage speculative research on the interactions and interrelationships between three key areas: social exclusion, transport and information and communications technologies (ICTs).

'Social exclusion' is understood in different ways by different practitioners and is endlessly redefined, yet the concept remains vague, its interpretation motivated often by political expediency or misunderstanding. This paper defines the term as the unique interplay between a number of dimensions, relating these dimensions of social exclusion to mobility and accessibility. The paper firstly seeks to uncouple poverty and exclusion, emphasising that exclusion can be experienced independently of poverty. Secondly, the paper identifies nine dimensions and, within each dimension, example potential exclusionary factors, of social exclusion. A mobility dimension to social exclusion is suggested, linking (lack of) access to adequate transport with the experience of social exclusion by reducing accessibility, to opportunities, social networks, goods and services, reinforcing other dimensions and factors of exclusion.

Latter sections of the paper turn to speculate upon reduction of mobility-related social exclusion. It is suggested that an increase in physical mobility sufficient to tackle mobilityrelated exclusion, by both private and public transport, whilst having some benefits for some 
people, is contrary to government environmental aims; is likely to be financially costly; will take a long time to introduce; and is unlikely to be able to meet all of the mobility needs of all of the population. The paper explores the concept that ICTs, specifically, the Internet, could help to provide accessibility without recourse to physical travel, which could alleviate some experience of exclusion within many of the dimensions of exclusion. The paper is cautious in its appraisal of the potential of virtual mobility to alleviate mobility-related exclusion, considering the likely benefits yet also discussing the limitations of virtual mobility, acknowledging problems of access to the Internet and the suggested social needs barriers to virtual mobility that are highlighted in current literature on this subject.

It should be noted at this juncture that, whilst drawing upon a strong literature regarding the impact of ICTs upon wider society, this paper discusses the implications of Internet-based virtual mobility upon the access needs of those experiencing mobility-related exclusion. Thus, the discussion is not one of substitution for existing physical mobility, nor of the potential of ICTs to increase physical mobility (although these perspectives are considered), but is one which questions whether, or not, the accessibility needs of those who currently find access to opportunities, social networks, goods and services problematic, because of limitations to physical mobility, could be fulfilled despite lack of access to physical travel.

\section{Poverty and social exclusion}

It is necessary to draw a firm distinction between social exclusion and poverty when seeking to understand the concept of social exclusion and its many causes and consequences. Poverty should be seen as just one dimension of exclusion. It is essential to recognise that the terms 
poverty and social exclusion are not synonymous, to allow exclusion to be seen in a wider context than the redistributive poverty debate allows.

Definitions of poverty have fluctuated with political fashions over the last century, motivated both by changing understandings of poverty, which suggested that there may be structural causes of poverty, challenging traditional perceptions of the morally delinquent and undeserving poor and by political expediency, in response to national and international political, economic, social and defence concerns (Peden, 1991). Initial understandings, resurrected to form the basis of non-interventionist policy during periods of right-wing government, were of 'absolute' poverty: a focus upon income poverty and the identification of a minimum level of income necessary for subsistence.

The key weakness of this definition of poverty is that it fails to recognise the differing circumstances and therefore income needs of different members of the population, assuming that 'there is always a fixed level of basic needs and an income which is insufficient to provide these needs defines the poverty line' (Foley, 1999:3). The concept of 'relative' poverty, where people are viewed as poor not in relation to a subsistence standard but to the standard of living experienced by others in the society in which they live (Burden, 2000), allows different definitions of poverty for individuals with different circumstances, living in different times. The definition allows for consideration of the multiple deprivations arising from inadequate income:

Individuals, families and groups in the population may be said to be in poverty when they lack the resources to obtain the types of diets, participate in the activities and have the living conditions and 
amenities which are customary, or at least widely encouraged or approved in the societies to which they belong.

Townsend, cited Golding, 1986:7

Thus, lack of access to a car is considered to be a characteristic of poverty today, featuring in the majority of deprivation indices (Foley, 1999; PAT 18, nd). Car ownership would not have been an appropriate measure of poverty thirty years ago when, or in a society where, car ownership was more restricted, the lack of access to a car less stigmatising and public transport and the urban environment were less influenced by the assumption of mass car ownership, such that car ownership was not a necessary instrument of social and economic participation.

Social exclusion, however, is a more complex concept than being poor. Table 1 highlights the key differences between poverty and social exclusion. The extension of the concept of poverty from absolute, subsistence to relative, ‘socially perceived necessities’ (JRF, 2000), incorporates a recognition of the consequences of lack of income but retains an economic focus upon material needs. 'Social exclusion' removes this economic and material focus (Levitas, 1998). Where poverty centres upon the outcomes of unequal access to material resources, social exclusion centres upon the processes of unequal access to participation in society (Duffy, 1998). Social exclusion refocuses the debate upon the effects of income-related deprivation upon the individual's place in society and their citizenship rights (CDF, nd; PercySmith, 2000). Where poverty is primarily distributional, social exclusion is relational, with a focus upon resource and power relationships between individuals, groups and the state (Dibben, 2001; Judge, 1995; Room, 1995). Policies to alleviate poverty focus upon the disparity between the top and bottom in society, moving people up from down; social 
exclusion's focus is upon moving those who are excluded from participation in society from out to in (Bhalla and Lapeyre, 1997; Duffy, 1998).

Table 1 inserted here.

This distinction between poverty and social exclusion allows for a recognition that poverty does not necessarily lead to exclusion; and that one can be excluded without being in poverty (Levitas, 1998; Oppenheim, 1998). The distinction raises awareness of non-material deprivations, recognising that exclusionary factors are not necessarily related to lack of income, or to each other (Foley, 1999), allowing separate analysis of and responses to exclusionary factors.

Many definitions of social exclusion, however, retain a focus upon material deprivations. This ‘redistributionist discourse’ (Levitas, 1998) focuses upon resource deprivation leading to exclusion from the community’s style of living:

[Social exclusion] is not only about shortage of money. It is about rights and relationships; and about how people are treated and how they regard themselves; about powerlessness, exclusion and loss of dignity. Yet the lack of adequate income is at its heart.

Church of England, cited Foley, 1999:4, emphasis added

Whilst this discourse broadens from economic exclusion to include consideration of social, political and cultural exclusions, linking these to the concept of reduced citizenship as a result (Lister, cited Levitas, 1998), the emphasis upon poverty as the prime cause of exclusion implies that a reduction in income poverty through redistribution is a solution to exclusion. 
Such a definition fails to acknowledge non-income related exclusionary factors, positing that poverty necessarily results in exclusion, that the income-rich cannot be excluded.

The authors suggest that to understand social exclusion, it is necessary to uncouple poverty and exclusion and to recognise both the income/material and the non-income/non-material causes and consequences of exclusion. Exclusion has not only economic, but multiple dimensions and characteristics (JRF, 2000; Percy-Smith, 2000; Walker and Walker, 1997). It is a heterogeneous concept, with interrelated causes and components which can, however, be experienced independently of each other and at different times, to different extents, by different individuals and groups.

In this paper, we define social exclusion as:

The unique interplay of a number of factors, whose consequence is the denial of access, to an individual or group, to the opportunity to participate in the social and political life of the community, resulting not only in diminished material and non-material quality of life, but also in tempered life chances, choices and reduced citizenship.

This definition, in highlighting the denial of access to opportunity, places emphasis upon structural constraints to participation, removing the individual culpability that is implied by definitions suggesting an inability to participate in society (Duffy, 1998; Walker and Walker, 1997). The powerlessness and denial of choice inherent in the social exclusion discourse prevents extension of the concept to those who self-exclude (for an opposing viewpoint, see 
Judge, 1995), for in the process of self-exclusion, one exercises the power of choice, which is denied to people experiencing social exclusion.

Within this definition is a recognition that the exclusion experienced by an individual in society is a result of a unique interplay between the dimensions and characteristics of exclusion specific to the circumstances of the individual. In recognising the unique experiences of exclusion, it is possible to appreciate that exclusion cannot necessarily be measured in a composite way, despite the political (and academic) expediency of measures of social exclusion. One cannot suggest that one person or group is more or less excluded than another person or group, following additive analysis of the number of characteristics of exclusion that they experience, for each individual or group will experience each characteristic to differing extents and to extents that vary according to the combination of characteristics experienced. Exclusion should not, therefore, be seen as a single, additive quality, in which characteristics are necessarily related, the sum of which is greater than each individual part (Bhalla and Lapeyre, 1997; Foley, 1999; PAT 18, nd). In addition, many of the characteristics of exclusion are non-quantifiable (Oppenheim, 1998), for example, powerlessness, self-esteem, isolation and perceptions of choice.

The ability to perceive exclusion as a unique combination of characteristics experienced by the individual allows us to place the person before the characteristics, avoiding generalisation and assumption regarding an individual's experiences. This conclusion places the individual at the centre, allowing an individual-centred approach to action against exclusion.

\section{Dimensions of exclusion}


Whilst it may not be possible to quantitatively measure social exclusion, the development of an understanding of the dimensions of exclusion can create a framework of understanding of the concept. A number of authors discuss the cultural, political and social, as well as the economic, dimensions of social exclusion (including Cahill, 1994; Desai, 1986; Goodin, 1996; Walker and Walker, 1997), both in relation to economic exclusion and as dimensions which stand alone. Table 2 expands beyond these dimensions to highlight nine key dimensions of exclusion, alongside examples of the potentially exclusionary factors that may be experienced within each dimension. Please note that the list of potential exclusionary factors is not exhaustive, but is included for illustrative purposes. An individual or group is likely to feel excluded where they experience one or more of these factors to be exclusionary (Percy-Smith, 2000:7).

Table 2 inserted here.

\section{A mobility dimension to exclusion}

Table 2 introduces a mobility dimension to exclusion. It can be suggested that lack of mobility is a contributory factor within each dimension and towards many exclusionary factors. Mobility-related exclusion does not refer to the transport-related poverty indicators used in many deprivation indices, but to spatial, temporal, financial and personal constraints (DETR, 2000b) upon the level of mobility necessary to enable participation in society.

This section firstly discusses mobility-related exclusion, before discussing the influence of mobility upon accessibility. The section then outlines some problems with solutions to mobility-related exclusion that involve an increase in physical mobility, either by private car or 
public transport, before speculating that virtual mobility could, in some circumstances, provide a viable alternative to an increase in physical mobility as a conduit towards inclusion.

What is mobility-related exclusion?

We define mobility-related exclusion as:

The process by which people are prevented from participating in the economic, political and social life of the community because of reduced accessibility to opportunities, services and social networks, due in whole or in part to insufficient mobility in a society and environment built around the assumption of high mobility.

The assumption of car ownership in the UK has resulted in both a culture and a landscape in which mobility is both expected and necessary to participate in society. In consequence, people with inadequate mobility can face reduced equality of opportunity and a reduced ability to participate in civic life (Dibben, 2001; Torrance, 1992). The car can be seen as a mechanical embodiment of the dominant political and cultural ideology in the latter quarter of the twentieth century - capitalist values of individualism, equality, freedom and progress (Gorz, 1979; Freund and Martin, 1993; Sachs, 1992, amongst others). Car ownership was encouraged and planning policy altered, in response to increases in car ownership and the value of distance. Changes in the location of employment, education, healthcare, leisure, shopping and, in consequence, social networks, have challenged the sustainability of localised existences. This has occurred alongside the decline of public transport, in terms of affordability, availability, accessibility and acceptability (DETR, 2000b), in response to decreased funding, decreased ridership and stigmatisation. In both the urban and rural 
environments, access to services, facilities and social networks has, for many, become problematic and sometimes impossible without access to a car. It should be emphasised at this juncture that the existence of a good public transport network does not necessarily indicate its accessibility. Where good public transport networks exists, for example, within a major city, particularly London, car ownership is often low and many people find that non-car ownership is no impediment to inclusion. However, the public transport may be the preserve only of the young, the (relatively) wealthy, non-disabled, people unencumbered with children or luggage, the confident or those travelling with companions, without concerns about safety. People in traditionally socially excluded groups can continue to experience mobility-related exclusion.

There is a danger in assuming that mobility-related exclusion cannot affect those with access to a car. The increasing costs of motoring affect those heavily reliant upon the car who cannot necessarily afford to meet these costs without making sacrifices in other areas of their lives (Root, 2000). In addition, in a single-car household, access to the car is likely to be unequally distributed with the effect that access 'on paper' may not translate to access in actuality. The reliance upon the car can itself be seen as an exclusionary factor, necessitating long periods of time travelling in isolation, curtailing social interaction, contributing to difficulties forming and maintaining social networks. The choice of when and where to travel, indeed, whether or not to travel and what to do with time and income is denied, not only to people with transport difficulties but to all citizens, whose lives are shaped by the need for mobility to access the goods, services and social networks that facilitate participation in society.

Mobility-related exclusion affects people at both the neighbourhood and the individual level (Church et al: 1999), often reinforcing other dimensions of exclusion. Poor neighbourhoods - 
urban and rural areas with a high incidence of people experiencing multiple exclusions (SEU, 1998) - tend to have low levels of motorised mobility: low levels of car ownership and poor road links alongside poor public transport links. Public transport often bypasses these areas, with the result that the neighbourhoods become 'no go' and 'no exit' communities (Murray, 1998). The poor availability, unreliability and high cost of public transport and the relatively time consuming nature of travel by public transport, especially for local travel, can reinforce other dimensions of social exclusion:

Those without cars usually need more time, greater effort and pay a higher marginal cost to reach the same destinations as people with cars.

DETR 2000b:18

The residents of poor neighbourhoods are often the most affected by the negative community, environmental, health and safety effects of increased car use (Berman, 1982; Grayling, 2001). However, not all people living in poor neighbourhoods experience mobility-related exclusion, nor will all people who experience mobility-related exclusion live in poor neighbourhoods, or be income poor. Mobility-related exclusion is not only clustered within poor neighbourhoods, but also scattered amongst individuals within the population (Grieco et al, 2000), disproportionately affecting people experiencing other exclusions (Whitelegg, 1997) - in particular, lone parents, older people and people with disabilities.

Barriers to the use of public transport, including low levels of service off-peak, poor facilities and accessibility of and at interchanges and onboard, the public transport environment and the cost of public transport, can reinforce low levels of accessibility, for many people. Nonmotorised mobility can be time consuming, unsafe and unhealthy. 'Modern landscapes seem 
to be designed for forty year old healthy males driving cars' (Ralph, cited Freund and Martin, 1993:45), creating an alienating environment for pedestrians, who must cross busy roads, walk around or walk beneath them in subways, each potentially dangerous activities, with accessibility, health and safety concerns (Wajcman, 1991).

Why does it matter? Mobility's accessibility function

Lack of accessibility is a key component of exclusion, influencing many dimensions of the social exclusion discourse. For people with constrained physical mobility, the viability of accessing many opportunities and services is severely reduced.

Transport difficulties can be a key barrier to employment, constraining the ability to travel to interview and to find out about employment opportunities, particularly where job centres are situated outside of areas with high unemployment. There is evidence that choice of job, or even the possibility of taking a job at all, in terms of location and working hours, particularly for jobs with off-peak working hours (part-time and shift work, which tend to be low skilled and low paid, with a predominantly female workforce), can be constrained by mobility difficulties. A 1999 Audit Commission study, cited by the DETR (2000b: 50) suggests that $52 \%$ of job seekers believe that lack of private transport has prevented them from getting a job and 23\% have been prevented from getting a job because of poor public transport.

The lack of accessible, affordable and available transport can also prevent access to educational and training opportunities and choices, for all age and skill groups. Access to leisure activities, hobbies and pursuits, important forms of relaxation and social interaction, often requires mobility, particularly in light of the (re)location of leisure facilities on the 
outskirts of towns and cities (Tomlinson, 1986; Torrance, 1992). The centralisation of health and other social services results in a requirement of mobility for accessibility. Access to out of town shopping facilities is dependent upon mobility, without which shoppers are reliant upon local shopping facilities, which often have a reduced level of choice of goods and charge higher prices (Murdock, 1986).

Mobility also has an important social function. It can be viewed as a social service (Cahill, 1994), facilitating social interaction and participation, whether at the destination or during the journey. Lack of mobility can reduce access to formal and informal social networks, increasing isolation and separation not only from goods and services but from social activities, family and friends.

\section{Tackling mobility-related exclusion}

At the launch of the Social Exclusion Unit in 1997, the Prime Minister, referred to transport as one of the major causes of exclusion:

[The purpose of the SEU is to address]... the damage dome [sic] by poor housing, poor education, lack of decent transport and above all, lack of work.

Tony Blair, cited Root, 1998, emphasis added

Both the white paper on integrated transport (DETR, 1998) and the ten year plan for transport (DETR, 2000a) highlight a relationship between social exclusion and (lack of) transport, a link made clear in the policy document, 'Social Exclusion and the Provision and Availability of Public Transport' (DETR, 2000b). More recently, the Social Exclusion Unit has launched a major consultation on transport and social exclusion (SEU, 2001), indicating the weight that is 
now given to this previously unacknowledged dimension of exclusion. It is suggested that, if transport is to be 'better for everyone', the transport system must consider the social implications of travel and restricted mobility (Hine and Mitchell, 2001). The conclusion drawn from both government and academic studies into the links between exclusion and transport tend to indicate a need for increased mobility to fulfil social needs and a role for transport in the creation of a fairer and more inclusive society (Church et al, 2000:12):

Enhancing social mobility requires more physical mobility... some people need both to be able to travel more and to accept the need to travel more if they are to be socially 'included'.

DETR, 2000c:5

Whilst improvement in the provision of public transport to actively consider and serve the needs of people who are socially excluded is to be welcomed and could help to alleviate some mobility-related exclusion for some people, it is unlikely that it could meet all of the mobility requirements, in terms for example of routes, timings, cost and physical accessibility, of all of the population. Whilst an improvement in the affordability, accessibility, acceptability and availability of public transport could increase use and thus decrease, it is unlikely to represent a solution, to mobility-related exclusion for all. Where reduction in the use of the private car is an aim of transport and environmental policy, it is unlikely that an increase in private mobility could represent a viable large-scale solution to mobility-related exclusion. In light of these concerns, could an alternative to motorised mobility as a facilitator of increased accessibility work alongside improvements in public transport in reducing mobility-related exclusion?

The primary function of mobility is to give access. Where mobility is inadequate, access can be denied and exclusion can occur. In this sense, lack of mobility can be seen to be a causal 
factor, but lack of access is the concerning consequence. When we think about increasing access, to tackle the outcome of a lack of mobility, rather than increasing mobility itself, we can consider the possibility of access via non-mobile, virtual means.

\section{Virtual mobility ${ }^{1}$}

'Virtual mobility' is a shorthand term for the process of accessing activities that traditionally require physical mobility, but which can now be undertaken without recourse to physical travel by the individual undertaking the activity. Thus, virtual mobility creates accessibility opportunities, both substituting for physical mobility and enabling access where previously there was an accessibility deficit.

'Virtual mobility' has been with us for many years - in fact, for as long as technology has allowed people to communicate in ways other than face to face, today allowing people to talk with friends and family and access goods by telephone, telegraph, fax or mail, receive news by radio or television, or to participate in leisure activities or education in the home, through the printed word. More recently, virtual mobility has come to refer to activities undertaken via the Internet and it is to this type of virtual mobility that this paper now refers. Examples of virtual mobility include: working from outside of the office (teleworking); conducting business online; creating new and maintaining old social networks online, in virtual communities and networked communities, via email and personal web pages; accessing health care and advice; formal and informal education; and shopping for goods online (teleshopping).

\footnotetext{
${ }^{1}$ The Internet is already being used with the aim of influencing travel. The provision of up to date traveller information aims to enable people to better plan their journeys, possibly enabling greater use of public transport; real time information aims to allow people to save time wasted in congestion or in waiting for public transport; and transport can become more responsive, with car sharing, car pooling and community mobility assistance schemes going online to allow faster matching of available service with mobility need. Virtual mobility is distinct from this traveller information.
} 
This research speculates that there is the possibility that virtual mobility could act as a supplement to physical mobility, enabling access to opportunities, social networks, goods and services without (necessarily) recourse to physical mobility by the person undertaking the activity. Table 2 (above) hypothesises nine dimensions of social exclusion and it has been suggested, within this paper, that (lack of) mobility influences a number of these dimensions of exclusion. This section now turns to consider the possible ways in which virtual mobility could provide an alternative to physical mobility, where a lack of mobility, through denial of access, results in the experience of social exclusion.

Research that has been undertaken in this area has been constrained by lack of popular use of the Internet until relatively recently. Society is still adapting and it is too early to predict with certainty the impacts of this medium upon society. Thus, the potential benefits of virtual mobility discussed here are largely speculative and on occasion may be uncorroborated by the current literature, or by existing web sites. The authors are thus aware that this section may read as a 'manifesto', advocating virtual mobility without challenge. However, the potential disbenefits of and restrictions upon virtual mobility are discussed in section 6 of this paper, below.

The lack of access to information about job opportunities is a significant barrier to employment and can be influenced by lack of mobility. The access to information online could enable the search for employment. Jobs can be (and are being) posted online ${ }^{2}$; one can download

\footnotetext{
${ }^{2}$ There are literally thousands of web sites in the UK advertising job vacancies, across the entire spectrum of the employment market, from professional to manual, Professorships to fork lift truck drivers. See, for example,
} 
application forms and apply for jobs by email; and people can post their curriculum vitae on dedicated web sites ${ }^{3}$. In addition, the informal networks through which much employment is gained can be recreated online, as can support networks for the unemployed, to boost morale, offer careers and training guidance and provide the contact with employed people that people in neighbourhoods with a high incidence of unemployment may lack ${ }^{4}$. Physical access to interviews and the jobs themselves could be made easier, through online traveller information and car sharing schemes.

Also in the economic dimension, alternative forms of credit can be accessed online, for example, community credit unions ${ }^{5}$ (Little et al, 2000) and local exchange and trading schemes (LETS) ${ }^{6}$ (Carter and Grieco, nd), where individuals can use their skills as credit, to 'buy' the skills, goods or co-operation of other members of the community (LETSystems, nd). The Internet could also provide a boost to the informal economy, allowing individuals to access markets, more easily trading goods and services, through local or national auction portals ${ }^{7}$.

In the social dimension, the Internet is increasing access to information and is extending the ability to access support groups, contact officials and access local authority services ${ }^{8}$. Information about housing, health, or online groups for people affected by crime, family

\footnotetext{
www.jobs.ac.uk, www.jobsite.co.uk, www.fish4jobs.co.uk and www.reed.co.uk. Some job centres are posting jobs online, accessible via www.employmentservice.gov.uk

${ }^{3}$ Again, these sites cover all sectors of the employment market, for example www.cvs.ac.uk, www.monster.co.uk and www.peoplebank.com, although there are more web sites dedicated to professional and clerical than to manual job hunters

${ }^{4}$ An example of advice and support for job hunters, including how to write a CV, or a covering letter, or where to look for employment, is at www.support4learning.org.uk/jobsearch/cvs.htm

${ }^{5}$ For example, www.leedscitycreditunion.co.uk, www.solis.co.uk/credit-union and www.scotwest.co.uk

${ }^{6}$ See, for example, www.letslinkuk.org and www.gmlets.u-net.com, each with links to community LETS

${ }^{7}$ For example, www.ebay.com and www.cqout.com

${ }^{8}$ E-government has been given a high priority by the current government, with the aim that all services be online by 2005 and that local authorities have a web presence and encourage two-way communication via their web sites.
} 
breakdown, or homelessness can help to support people affected by the negative social effects of exclusion. Importantly, virtual mobility can provide access to officials, enabling people to discuss problems and develop solutions - for example, reporting housing faults online, or ordering a replacement orange (parking) badge - without physically attending a meeting, which is often prevented by mobility, income and time constraints ${ }^{9}$. Carter and Grieco (nd) postulate the possibility of community policing online, allowing community members to inform about crime without travelling to the police station and with reduced fear of reprisal.

It is in the social networks dimension that virtual mobility has been most proven as a viable alternative to physical mobility, helping to reduce loneliness and isolation by providing virtual access to both new and old friends and family. Through the use of bulletin board systems and chat rooms, it is possible to move between social spaces without physical mobility (Jones, 1995), gaining information support, esteem support and social companionship (Pleace et al, 2000). This form of social support could be useful not only for people who find it physically difficult to access social networks, because of personal characteristics, economic or spatial difficulties, but also for people who find communication difficult, because, for example, of low self esteem or confidence. The stigma of accessing social support (Mickelson, 1997), can be overcome online, as people access information to enable self-help, or anonymously ask for support and assistance.

Through the Internet, families and friends can keep in touch (Age Concern, 2001; Cyberatlas, 2001). New contacts can be made and sustained in virtual communities - non-geographical

See www.e-envoy.gov.uk. A particularly good example of online community information, provided by the local authority, is at www.hants.gov.uk 
communities of people who have met on the Internet (Rheingold, 2000; Wellman, 1999). Geographical communities can be revived in networked communities, through:

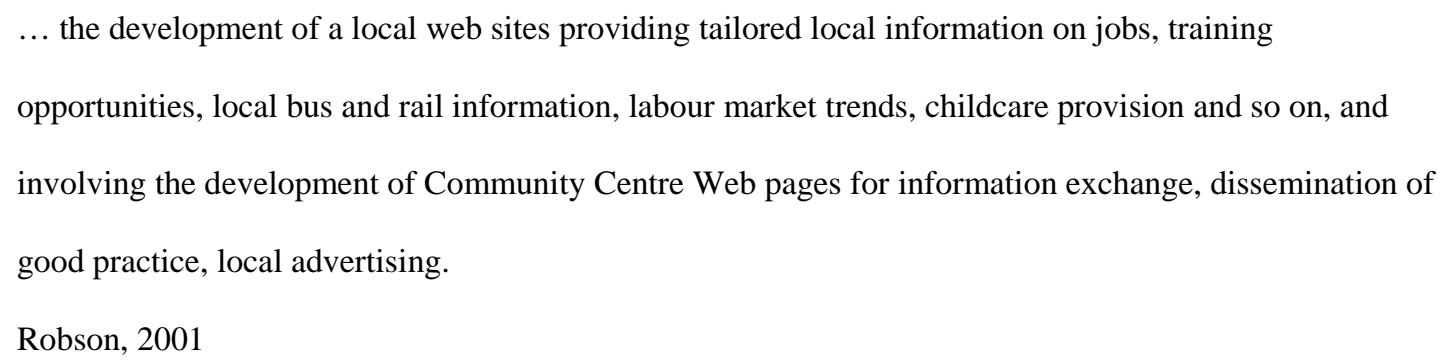

There are numerous examples in the literature of the success of both virtual and networked communities in reducing exclusion through the provision of access to social support networks. Rheingold (2000) gives examples of the social support given by members of 'the WELL', a virtual community in America, most graphically the support given to the parents of a child with Leukaemia and the support network which arose within the virtual community following the suicide of a fellow WELL member. Wellman (1999) discusses the reciprocal relationships between virtual community members, defending the use of the term 'community' to describe a non-geographical entity thus:

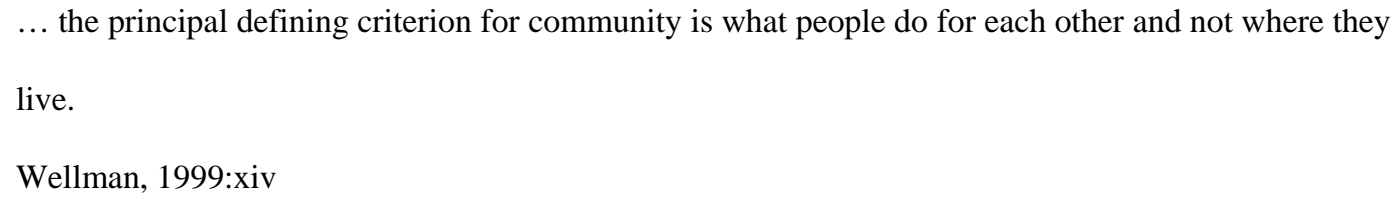

The revival of community as a result of the introduction of online centres, providing access to the Internet and, through this, to community care, activities, support, advice, information and,

\footnotetext{
${ }^{9}$ The authors are as yet unaware of local authorities allowing this form of communication but refer the reader again to the government's aim of having all services online by 2005
} 
most importantly, a community forum, is documented by authors including Harris and Dudley (2000), Mele (1999) and Shearman (1999), illustrating the power of ICT in reducing isolation, broadening the horizons and empowering communities and thus the individuals within.

Political participation, in parties, pressure groups and local/national government can be highly restrictive, requiring resources including time, money and 'cultural capital' - most commonly, education, confidence and contacts (Ward, 1986) - and mobility. Through virtual mobility, people can be given a voice and can express their views, gain information and participate in debate without the need for physical attendance at official council ${ }^{10}$ or party/pressure group meetings ${ }^{11}$, overcoming some of the temporal, confidence, financial and mobility constraints. In assisting access to information and to officials, to each other and to sources of support, communities could become politically empowered. Shearman (1999:18) suggests that this could 'change the power relationship between citizen and state', changing the opportunities to express opinions, giving access to both like-minded and opposite-minded people and allowing people to express their views in ways in which they could be more confident.

The increased opportunity for participation in democracy and the exercise of authority as a result of the removal of the physical mobility barrier was postulated by Day and Harris (1997) and Jones (1995) and has since been observed. Mele (1999) details the fight by the citizens of Jervay to gain control of the redevelopment of their housing estate, gaining access to decision

\footnotetext{
${ }^{10}$ As yet, participation in local government online is limited and varies according to the local authority. Participation at a national level is encouraged via online consultation documents - however, participation is to an extent limited in this way to things that the government want the public to feedback on, rather than allowing the public to freely feedback to the same level of official approval and encouragement. www.nottinghamcity.gov.uk is a particularly advanced citizens web site; and you can find a number of government consultation documents via www.cabinet-office.gov.uk
} 
makers, to information and to support from people fighting similar battles in other neighbourhoods, to sympathisers offering skilled support and to other members of the affected community, without recourse to physical mobility.

Through access to information, individuals could also become empowered to shape their own future, including their own health and social care and support (Burrows et al, 2000). Through access to self help and support groups, especially with regard to healthcare ${ }^{12}$, people could become aware of choices through being more informed, without having to have the skills, confidence or mobility to access libraries or meet with officials. Through virtual mobility, some physical and mental health impairments which act as constraints upon physical mobility and thus access to social networks ${ }^{13}$, goods and services can be overcome. The discrimination that is inherent in social attitudes, affecting equality, could be masked by recourse to virtual mobility (Baym, 1995). Online learning ${ }^{14}$ can allow people to improve their educational achievement and skills, without having to travel or meet in person, a potential barrier to learning because of lack of confidence, transport difficulties, personal circumstances (Robson, 2001; Shearman, 1999).

\footnotetext{
${ }^{11}$ There are a great number of pressure groups online and all major parties in the UK have a web site, many with local branch web sites. Whilst the majority are focussed on distributing outward information, there are some through which members can feedback and debate

12 There are thousands of health information web sites and even more support groups, for many illnesses, empowering users vis-à-vis the medical profession, which is often perceived as a disempowering force. In this sense, the web is not only a source of support, but also performs the role of a social leveller. Some web sites give feedback on medical conditions, placing users in touch with nurses or specialists, often at no cost - although care should be exercised in assessing the accuracy of medical web sites. See www.nhsdirect.nhs.uk, www.netdoctor.co.uk, www.cyberdocs.com. www.ebvonline.org provides a link to the community doctor, with whom residents can have an online consultation

${ }^{13}$ As one example, the RNIB offer a 'webpals' service, allowing people with similar conditions to talk with each other www.rnib.org.uk. The web site also offers advice and access to and help with campaigns

${ }^{14}$ See especially www.learndirect.com, which provides access to and information about education and training at all levels, or www.open.ac.uk for a long standing example of distance learning at a higher academic level
} 
Finally, whilst virtual mobility cannot create time, it could enable people to use time more effectively, eliminating the need to travel to work, to access social networks and to access goods and services, for example, shopping, or care support. Thus, people could get more quality time out of the time available, allowing them to 'double count time' - conducting more than one activity concurrently, for example, shopping online whilst supervising child's play.

\section{A virtual mobility-related dimension?}

Access to virtual mobility has the potential to be as problematic as access to physical mobility. This section discusses three key objections to the potential of virtual mobility: the 'digital divide'; the potential social impacts of virtual mobility; and the potential transport implications of virtual mobility.

There is evidence to suggest that there is a 'digital divide' in the UK: a gap in access to ICTs that is determined by an individual's characteristics. This suggests that people who experience social exclusion are highly likely to also be excluded from access to the Internet and that, without access to the Internet, disadvantage and exclusion will be further reinforced (Graham and Marvin, 1999, PAT 15, 2000). It is difficult to access data on Internet access for the majority of marginalised groups. However, it is clear that Internet access is highly variable according to income and class. Just 7\% of households in the lowest income decile having access to the Internet, compared to $71 \%$ of households in the highest decile ${ }^{15}$. In examining the statistics by class, we see that $78 \%$ of households in social class A have access to the

\footnotetext{
${ }^{15}$ National Statistics (2001) 'Internet Access 26 June 2001' http://www.statistics.gov.uk/pdfdir/int0601.pdf, viewed 01/11/01
} 
Internet, compared to $27 \%$ of households in social class $\mathrm{E}^{16}$. We can suggest that the majority of people who experience social exclusion are also vulnerable to poverty; and that class and income are directly related to education and skills; employment; family circumstances; and absence of disability.

The financial barrier to in-home connection is clear, not only in terms of initial purchase of hardware and software, but in paying for and sustaining telephone line connection. For some households, gaining credit approval for line rental, which often demands that the user has a bank account and available credit, is impossible. Access to the Internet also requires skills, knowledge and, importantly, exposure, most often in the workplace or via family and friends, without which both the ability and the inclination to go online will be lacking. The influence of other dimensions of exclusion, including temporal and financial constraints, plus personal factors, such as lack of confidence, or childcare, may represent barriers to gaining the skills needed to participate in virtual mobility. Finally, the digital divide is also evidenced in a lack for relevant content for all groups and the ineffective marketing of the Internet as a tool for all people, for more than just shopping and banking (Graham 2000, Hellawell, 2001). It is unlikely that people will seek to access the Internet without education in the potential benefits of these technologies.

In light of the above, we can suggest that people who experience mobility-related exclusion are also likely to be vulnerable to virtual-mobility-related exclusion. However, there are a number of initiatives that aim to extend access, providing access to bridge the digital divide.

\footnotetext{
${ }^{16}$ National Statistics (2001) 'Internet Access 27 March 2001’http://www.statistics.gov.uk/pdfdir/int0301.pdf, viewed 01/11/01
} 
Government funded initiatives including Wired Up Communities ${ }^{17}$, which aim to place the Internet into homes, Computers Within Reach ${ }^{18}$, allowing people to rent or buy affordable PCs and community initiatives, for example, Redbricks ${ }^{19}$, where community members developed locally maintained access to the Internet for a flat rate, low monthly charge.

In-home access could also create problems because of the lack of on-hand technical support and training. UK Online centres, supported and promoted by the UK government (DoEE, 2001), provide computer and Internet facilities and training, often free of charge, at a central location within a community (Day and Harris (1997); Robson (2001); Shearman (1999); Stepulevage and Thomas (2001); Wilcox (nd)). Many communities also provide online facilities ${ }^{20}$. However, physical mobility is necessary to access these facilities and confidence is needed to learn with and in front of others, factors which may, in combination with other factors, reduce accessibility of the centres:

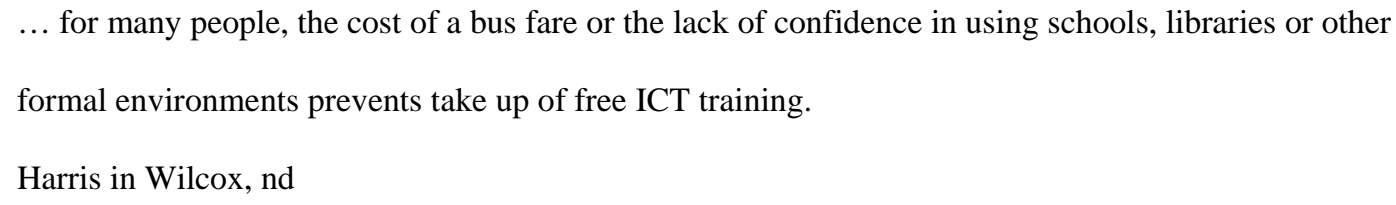

The physical accessibility of the technology used to facilitate virtual mobility is an issue for concern. Many people who are excluded from physical mobility could be excluded from virtual mobility, exacerbating disadvantage, if the technology is not designed for all.

\footnotetext{
${ }^{17}$ More information available via www.dfee.gov.uk/wired/over.shtml

${ }_{18}^{18}$ More information available via www.e-envoy.gov.uk

${ }^{19}$ www.redbricks.org.uk

${ }^{20}$ More information about such organisations via www.tvco.org.uk and www.stockton-online.ac.uk
} 
There are concerns about the community and social effects of virtual mobility, concerning the decline of human relations; the importance of face-to-face and physical contact; an increase in social isolation; deception and misrepresentation in the online world; and the decline of community (Adams, 2000; Graham, 2000; Hamburger and Ben-Artzi, 2000, Cornwell and Lundgren, 2001). Other commentators emphasise that community is not a 'zero sum game' (Wellman, 1999:348), where membership of one community necessitates withdrawal from another, suggesting that relations in the online world are as satisfying as those in the offline world, if not more so, allowing the creation of communities of interest over geography and the reduction of social isolation (Rheingold, 2000, Negroponte, cited Schon, 1999; Baym, 1995). The extent to which social networks can be sustained online and to which virtual mobility will exacerbate isolation and neighbourhood decline, rather than alleviating it, if people withdraw from local communities into online communities, is an important area of debate. However, there is little writing of substance that suggests that either side in the debate has the upper hand. Whilst literature on the benefits of online communities frequently cites online episodes as evidence of true community feeling, much of the literature on the social impacts of the Internet remains speculative at this early stage in the mass adoption of Internet technologies.

Finally, the transport effects of virtual mobility. The effects of ICTs on transport have long been discussed, in relation to teleworking. Salomon (1986) presents three possible outcomes of the interaction between ICTs and transport: substitution - the replacement of journeys as a result of the use of ICTs; complementarity - where technologies and transport work together and there is no trade-off between the two; and enhancement, where the number of trips actually increases as a result of the use of ICTs. These themes have since been revisited in light of the Internet (Black, 2001; Graham, 1998; Graham and Marvin, 1999; Niles, 1994; Golob and 
Regan, 2001). Where the majority of commentators believe that virtual mobility will lead to an increase in travel, in response both to the increase in free time available for leisure travel following the eradication of previously necessary travel, for example, the daily commute or the shopping trip and in increasing an individual’s 'perceptual space’ (Graham and Marvin, 1999; also Black, 2001), increasing demand to travel to far away places, others, specifically Golob and Regan (2001:114), suggest in contrary that:

\footnotetext{
As we become busier, we will increasingly rely on IT to avoid unnecessary travel... Also, as we spend new time engaged in telecommunications, there will simply be less time available for other activities, including travel. Small effects by a very large number of persons will aggregate up to large effects on a system wide basis.
}

It is true that earlier forms of ICT, including the telephone, wireless, telegraph, mail, radio and television, have not led to a reduction in the amount of travel - indeed, that travel has increased apace with advances in ICTs. However, the imperative to reduce travel and the disbenefits to the individual of travel have never before been as stark as today; nor has such rapid adoption or development of ICT been observed. In short, we cannot know the impacts of virtual mobility upon physical mobility - we can only speculate. This paper has aimed to introduce the concept of virtual mobility as a supplement to physical mobility for those for whom physical travel is problematic and as such we would anticipate little change in physical mobility amongst these groups.

\section{Conclusions}

This paper has sought to highlight the differences between poverty and social exclusion, emphasising that one can be excluded without being poor and can be poor without being 
excluded, enabling an understanding of the multiple dimensions and characteristics of exclusion. In introducing a mobility dimension to social exclusion, linking a lack of mobility to lack of access to elements that are essential to enable participation in modern society, it is possible to consider mobility-related causes of and thus solutions to some aspects of exclusion.

It is not suggested that all exclusion is related to accessibility difficulties; nor that the promotion of accessibility could alleviate exclusion for all people in all dimensions. However, action to increase accessibility to opportunities, social networks, goods and services could influence some dimensions of exclusion. The paper has sought to demonstrate that increased physical mobility, by car or public transport, could be problematic and, on its own, may not provide a fully viable or sustainable solution to mobility-related exclusion. The paper continues to speculate that use of new technologies could enable a new mobility and a new accessibility, despite current concerns about access to new technologies and the social and transport implications of virtual mobility, as an alternative to an increase in physical mobility.

The discussion of the possible influence of virtual mobility upon the dimensions of exclusion is, by necessity, speculative, as is much research into the impacts of the Internet, because the movement of the Internet into the mainstream has only recently occurred. The aim of this paper has been to lay the foundations for future research in this area. On-going research by the authors will observe the influence of virtual mobility upon accessibility and experiences of exclusion, to uncover the benefits and limitations of this new mobility and the extent to which virtual mobility could or should be considered as part of an integrated transport policy, which has the reduction of exclusion and disadvantage as its aim. 


\section{References}

Adams, J. 2000. Hypermobility. Prospect. Accessed via http://www.prospectmagazine.co.uk/highlights/hypermobility/, viewed 23/02/01.

Age Concern. 2001. IT revolution strengthens family ties. http://www.ace.org.uk/SiteArchitek/news.nsf/d268e7e7eea08ab74125675b00364294/8 5c2893eedacefef80256a4200575a1b!OpenDocument. Viewed 26/06/01.

Baym, N.K. 1995. The emergence of community in computer mediated communication. In Jones, S. 1995. Cybersociety: computer mediated communication and community. London: Sage Publications.

Berman, M. 1982. All That Is Solid Melts Into Air: the experience of modernity. London: Verso.

Bhalla, A., Lapeyre, F. 1997. Social exclusion: towards an analytical and operational framework. Development and Change 28 , 413-433.

Black, W.R. 2001. An Unpopular Essay on Transportation. Journal of Transport Geography. 9, $1-11$

Burden, T. 2000. Poverty. In Percy-Smith, J. 2000. Policy Responses to Social Exclusion: towards inclusion? Buckingham: Open University Press.

Burrows, R., Nettleton, S., Pleace, N., Loader, B., Muncer, S. 2000. Virtual community care? Social policy and the emergence of computer mediated social support. ICS 3(1). http://www.infosoc.co.uk00109/feature.htm, viewed 06/02/01.

Cahill, M. 1994. The New Social Policy. Oxford: Blackwell Publishers.

Carter, C. and Grieco, M. nd. New deals, no wheels: social exclusion, tele-options and electronic ontology. http://www.geocities.com/margaret_grieco/working/wheels.html, viewed 23/4/01. 
CDF. Nd. Social Inclusion and community development practice. http://www.cdf.org.uk/html/socinc.html 06/02/01.

Church, A., Frost, M., Sullivan, K. 2000. Transport and social exclusion in London. Transport Policy (7 ), 195-205.

Cornwell, B. and Lundgren, D.C. 2001. Love on the Internet: involvement and misrepresentation in romantic relationships in cyberspace vs. realspace. Computers in Human Behaviour. 17, 197-211.

Cyberatlas. 2001. Moms using web to bring families together. http://cyberatlas.internet.com/big_picture/demographics/print/0,,5901_705131,00.html, viewed 06/03/01.

Day, P., Harris, K. 1997. Down-to-Earth Vision: community based it initiatives and social inclusion. http://www-5.ibm.com/uk/community/uk171.pdf, viewed 03/03/01.

Desai, M. 1986. Drawing the line: on defining the poverty threshold. In Golding, P. (ed). 1986. Excluding the Poor. London: Child Poverty Action Group.

DETR. 1998. A New Deal For Transport: better for everyone. London: DETR.

DETR. 2000a. Transport 2010: the 10 year plan. London: DETR.

DETR. 2000b. Social Exclusion and the Provision and Availability of Public Transport. London: DETR.

DETR. 2000c. Social Exclusion And The Provision And Availability Of Public Transport: summary. London: DETR.

Dibben, P. 2001. Transport and social exclusion in rural areas. Proc. UTSG $33^{\text {rd }}$ Annual Conference 3-5 Jan 2001, St Anne’s College, Oxford. 
DoEE. 2001. 1200 UK online centres help make internet access.

http://getting.ukonline.gov.uk/news/news75.htm, viewed 14/03/01.

Duffy, K. 1998. Combating social exclusion and promoting social integration in the European Union. In Oppenheim, C. 1998. An Inclusive Society? Strategies for tackling poverty. London: IPPR.

Foley, K. 1999. Getting the Measure of Social Exclusion. London: London Research Centre. Freund, P., Martin, G. 1993. The Ecology of the Automobile Montreal: Black Rose Books.

Golding, P. 1986. Introduction. In Golding, P. (ed). 1986. Excluding the Poor. London: Child Poverty Action Group.

Golob, T.F. and Regan, A.C. 2001. Impacts of information technology on personal travel and commercial vehicle operations: research challenges and opportunities. Transportation Research Part C. 9, 87-121.

Goodin, R. 1996. Inclusion and Exclusion. Archives Europeennes de Sociologie. 37(2), 34337.

Gorz, A. 1979. Ecology as Politics. London: Pluto.

Graham, S. 1998. The end of geography or the explosion of place? Conceptualising space, place and information technology. Progress in Human Geography. 22,2, 165-185.

Graham, S. and Marvin, S. 1999. Planning cyber-cities? Integrating telecommunications into urban planning. Town Planning Review. January 1999.

Graham, S. 2000. Bridging urban digital divides? Urban polarization and information and communications technologies (ICTs): current trends and policy prospects. Background paper for the United Nations Centre for Human Settlements (UNHCS) August 2000. Unpublished. 
Grayling, T. 2001. Transport and social exclusion. Transport Statistics User Group meeting, 24 January 2001. Institute for Public Policy Research: Unpublished.

Grieco, M., Turner, J., Hine, J. 2000. Transport, employment and social exclusion: changing the contours through information technology. http://www.geocities.com/transport_and_society/newvision.html, viewed 07/03/01.

Hamburger, Y.A. and Ben-Artzi, E. 2000. The relationship between extraversion and neuroticism and the different uses of the Internet. Computers in Human Behaviour. 16, 441-449.

Harris, K. Dudley, M. 2000. Many First Steps: interim report to DTI and DfEE Learning Centres Board on the first phase of the five Pioneer Learning Centres revised edition. http://www.defee.gov.uk/ukonlinecentres/report1.htm, viewed 14/03/01.

Hellawell, S. 2001. Beyond Access: ICT and social inclusion. London: Fabian Society.

Hine, J. Mitchell, F. 2001. Better for everyone? Travel experiences and transport exclusion. Urban Studies. 38(2), 319-332.

Jones, S.G. 1995. Cybersociety: computer mediated communication and community. London: Sage Publications.

JRF. 2000. Poverty and social exclusion in Britain. http://www.jrf.org.uk/knowledge/dindings/socialpolicy/930.htm, viewed 24/10/00. Judge, A. 1995. Social Exclusion: a metaphoric trap? Moving beyond false dialogue. Proc. The European Continental Forum on Citizenship and Ways out of Social Apartheid Paris 16-17 February 1995.

LETSystems. Nd. http://www.gmlets.u-net.com/explore/home.html, viewed 27/06/01.

Levitas, R. 1998. The Inclusive Society? Social Exclusion and New Labour. Hampshire: MacMillan Press Ltd. 
Little, S., Holmes, L., Grieco, M. 2000. Calling up culture: information spaces and information flows as the virtual dynamics of inclusion and exclusion. http://www.geocities.com/stephen_e_little/callup.html, viewed 23/4/00.

Mele, C. 1999. Cyberspace and disadvantaged communities: the Internet as a tool for collective action. In Kollock, P., Smith, M. (eds). 1999. Communities in Cyberspace. London: Routledge.

Mickelson, K.D. 1997. Seeking social support: parents in electronic support groups. In Kiesler, S. (Ed). 1997. Culture of the Internet. Mahwah: Lawrence Erlbaum Associates

Murdock, G. 1986. Poor connections: income, inequality and the 'information society'. In Golding, P. (Ed). 1986. Excluding the Poor. London: Child Poverty Action Group. Murray, S. 1998. Social Exclusion and Integrated Transport. http://www.art.man.ac.uk/transres/socexclu5.htm, viewed 24/10/00.

Niles, J.S. 1994. Beyond Telecommuting: a new paradigm for the effect of telecommunications on travel. http://www.lbl.gov/ICSD/Niles, viewed 15/11/01.

Oppenheim, C. 1998. Poverty and social exclusion: an overview. In Oppenheim, C. (Ed). 1998. An Inclusive Society? Strategies for tackling poverty. London: IPPR.

PAT 15. 2000. Closing the Digital Divide: information and communication technologies in deprived areas: a report by Policy Action Team 15. London: DTI

PAT 18. Nd. Working Paper: Measuring Deprivation: a review of indices in common use. http://www.cabinet-office.gov.ukseu/2000.pat18/Depindices.htm, viewed 07/03/01.

Peden, G.C. 1991. British Economic and Social Policy: Lloyd George to Margaret Thatcher. Oxford: Philip Allen. 
Percy-Smith, J. 2000. Policy Responses to Social Exclusion: towards inclusion? Buckingham: Open University Press.

Pleace, N., Burows, R., Loader., B, Muncer., S and Nettleton., S. 2000. On-line with friends of Bill W: social support and the net. Sociological Research Online 5:2 http://www.socresonline.org.uk/5/2/pleace.html, viewed 06/02/01.

Rheingold, H. 2000. The virtual community: homesteading on the electronic frontier. Massachusetts: MIT.

Robson, M. 2001. Case Study: Shipley Communities Online. http://ferl.becta.org.uk/frames/sctudies/ShipleyCollege/OnlineCommunities.htm, viewed 08/03/01.

Room, G. 1995. Poverty in Europe: competing paradigms of analysis. Policy and Politics 23(2),103-113.

Root, A. 1998. Home Alone. Transport Retort. January, 11

Root, A. 2000. Transport and Communications. In Halsey, A.H. and Webb, J. (Eds). 2000. $20^{\text {th }}$ Century British Social Trends Vol. 1 . New York: St Martin’s Press

Sachs, W. 1992. For Love of the Automobile. Oxford: University of California Press.

Salomon, I. 1986. Telecommunications and travel relationships: a review. Transportation Research A. 20, 223-238.

Schön, D.A. 1999. Introduction. In Schön, D.A., Sanyal, B. and Mitchell, W.J. (eds). 1999. High Technology and Low-Income Communities: Prospects for the Positive Use of Advanced Information Technology. Mass: MIT Press

SEU. 1998. Bringing Britain Together: a national strategy for neighbourhood renewal. London: TSO. 
SEU. 2001. Transport and social exclusion consultation.

http://www.socialexclusionunit.gov.uk/2001/Transport/transport.htm, viewed 15/09/01.

Shearman, C. 1999. Local Connections: making the net work for neighbourhood renewal. London: Communities Online.

Stepulevage, L. and Thomas, G. 2001. Newham Online: evaluation and outlook. Report submitted to Newham Online and the Government Office for London. http://www.newham.org.uk/Library/Articles/Neon-Evaluation-2001.html, viewed $24 / 04 / 01$.

Tomlinson, A. 1986. Playing away from home: leisure, disadvantage and issues of income and access. In Golding, P. (Ed). 1986. Excluding the Poor. London: Child Poverty Action Group.

Torrance, H. 1992. Transport for all: equal opportunities in transport policy. In Cleary, J., Hamilton, K., Hanna, J., Roberts, J. (Eds). Travel Sickness: the need for sustainable transport policy for Britain. London: Lawrence Wishart.

Townsend, P. 1986. Forward. In Golding, P. (Ed). 1986. Excluding the Poor. London: Child Poverty Action Group.

Wajcman, J. 1991. Feminism Confronts Technology. Oxford: Polity Press.

Walker, A., Walker, C. 1997. Britain Divided: The growth of social exclusion in the 1980s and 1990s. London: CPAG.

Ward, S. 1986. Power, Politics and Poverty. In Golding, P. (Ed). 1986. Excluding the Poor. London: Child Poverty Action Group.

Wellman, B. (Ed). 1999. Networks in the Global Village: life in contemporary communities. Oxford: Westview Press.

Whitelegg, J. 1997. Critical Mass. London: Pluto Press. 
Wilcox, D. Nd. How new technology can help the socially excluded in the Knowledge Society. http://www.housit.org.uk/articles/wilcox/socxtext.htm, viewed 06/02/01. 


\begin{tabular}{|l|l|}
\hline \multicolumn{1}{|c|}{ Poverty } & \multicolumn{1}{c|}{ Social exclusion } \\
\hline Material resources & Participation in society \\
\hline Distributional & Relational \\
\hline Outcomes & Processes \\
\hline Economic rights & Citizenship rights \\
\hline Up from down & In from out \\
\hline Uni-dimensional & Multiple dimensions \\
\hline Easily quantifiable & Difficult to quantify \\
\hline
\end{tabular}

Table 1. Some important distinctions between poverty and social exclusion 


\begin{tabular}{|c|c|}
\hline Dimension & Potentially exclusionary factors \\
\hline Economic & $\begin{array}{l}\text { Income poverty } \\
\text { Unemployment } \\
\text { Lack of access to 'safety net' credit facilities } \\
\text { Lack of access to technology }\end{array}$ \\
\hline Societal & $\begin{array}{l}\text { Crime } \\
\text { Family dynamics } \\
\text { Poor education } \\
\text { Inequality } \\
\text { Lack of social rights } \\
\text { Lack of access to appropriate health and social care }\end{array}$ \\
\hline Social networks & $\begin{array}{l}\text { Breakdown of formal and informal networks } \\
\text { Loneliness } \\
\text { Isolation } \\
\text { Lack of information } \\
\text { Social attitudes }\end{array}$ \\
\hline $\begin{array}{l}\text { Organised political } \\
\text { (ability to influence } \\
\text { decision making at an } \\
\text { organised level) }\end{array}$ & $\begin{array}{l}\text { Disenfranchisement (low turnout/registration) } \\
\text { Low participation in groups and organisations } \\
\text { Denial of citizenship rights and freedoms } \\
\text { Lack of representation } \\
\text { Inability to participate in the exercise of authority }\end{array}$ \\
\hline $\begin{array}{l}\text { Personal political (ability } \\
\text { to make decisions over } \\
\text { own life) }\end{array}$ & $\begin{array}{l}\text { Powerlessness } \\
\text { Restricted choices }\end{array}$ \\
\hline Personal & $\begin{array}{ll}\text { Impairment } & \text { Gender } \\
\text { Ethnicity } & \text { Religion } \\
\text { Culture } & \text { Sexuality } \\
\text { Class } & \text { Health } \\
\text { Skill levels/educational achievement } & \end{array}$ \\
\hline Living space & $\begin{array}{l}\text { Neighbourhood, including safety, crime } \\
\text { Poor local environment } \\
\text { Disunity of community } \\
\text { Geographical isolation (accessibility) } \\
\text { Local services, including transport, education } \\
\end{array}$ \\
\hline Temporal & Time poverty \\
\hline Mobility & $\begin{array}{l}\text { Poor or unavailable transport } \\
\text { Reduced accessibility to social networks, facilities, goods and } \\
\text { services }\end{array}$ \\
\hline
\end{tabular}

Table 2. Dimensions and potential exclusionary factors of social exclusion 